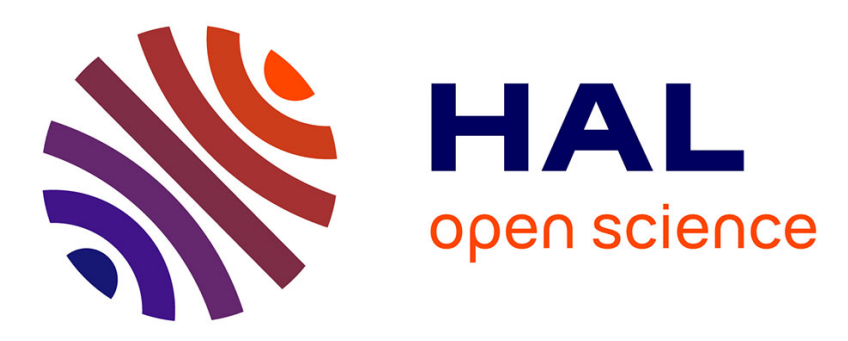

\title{
Data acquisition and online processing for the Virgo experiment
}

D. Verkindt, F. Bellachia, R. Flaminio, L. Fournier, F. Marion, A. Masserot, B. Mours

\section{- To cite this version:}

D. Verkindt, F. Bellachia, R. Flaminio, L. Fournier, F. Marion, et al.. Data acquisition and online processing for the Virgo experiment. Marcel Grossmann Meeting on General Relativity 9, Jul 2000, Rome, Italy. pp.1925-1926. in2p3-00012805

\section{HAL Id: in2p3-00012805 https://hal.in2p3.fr/in2p3-00012805}

Submitted on 23 May 2003

HAL is a multi-disciplinary open access archive for the deposit and dissemination of scientific research documents, whether they are published or not. The documents may come from teaching and research institutions in France or abroad, or from public or private research centers.
L'archive ouverte pluridisciplinaire HAL, est destinée au dépôt et à la diffusion de documents scientifiques de niveau recherche, publiés ou non, émanant des établissements d'enseignement et de recherche français ou étrangers, des laboratoires publics ou privés. 


\title{
DATA ACQUISITION AND ONLINE PROCESSING FOR THE VIRGO EXPERIMENT
}

\author{
D. VERKINDT, F. BELLACHIA, R. FLAMINIO, L. FOURNIER, \\ F. MARION, A. MASSEROT, B. MOURS \\ LAPP, Chemin de Bellevue, BP110, 74940 ANNECY-LE-VIEUX, FRANCE
}

\begin{abstract}
Gravitational Waves Experiments like Virgo will acquire a large amount of data. The scheme of the data acquisition currently installed on Virgo site and the planned Online Processing (h reconstruction, data quality and Online preselection) aiming at the data flow reduction are described.
\end{abstract}

\section{Virgo Data Acquisition}

\subsection{Introduction}

A $3 \mathrm{~km}$ long interferometric detector like Virgo needs to acquire interferometer output data and environment monitoring data according to some specifications:

- Some parts of data acquisition will be $3 \mathrm{~km}$ away.

- Some environment monitoring at $20 \mathrm{kHz}$ is assumed.

- Interferometer feed-back loops data are must be monitored.

- all the data acquisition must be synchronized.

- the recorded data format if frames ${ }^{1}$.

This implies to implemented some specific hardware and software.

\subsection{General scheme}

Virgo Data Acquisition has been subdivided into three parts ${ }^{2}$ :

- data from the output of the interferometer (detection bench)

- data from alignment and feed-back systems (controls)

- data from environment monitoring

This gives us the advantage of quasi-independent data acquisitions implying some flexibility in the debugging before and during the commissioning steps.

All the data acquisition is synchronized using a home made timing system based on a GPS board, a set of timing boards and optical fibers. The timing system delivers a base clock at $2 \mathrm{MHz}$, a sampling frequency of $20 \mathrm{kHz}$ and a frame frequency of $1 \mathrm{~Hz}$.

For each of the three data acquisition parts, data are formatted into frames ${ }^{1}$ and sent on 100 Mbps Ethernet network by dedicated softwares: the Frame Builders.

\subsection{Dynamical connection scheme}

Almost all data acquisition hardware and software is now installed on Virgo site and tests are under way with the detector parts that can already deliver data.

A general philosophy has been adopted for the data acquisition at the level of frame builders: the dynamical connection. It allows some flexibility. Data 
acquisition is then like a tool box, each tool independent of the others. In practice, any user trying to connect to a frame builder (for instance with a data display) first sends a request to it through the network in order to be added as a consumer of this frame builder.

Moreover a separation is made between the data acquisition's world and the user's world by dividing each Main Frame Builder into two independant processes that communicate through a shared memory.

\section{Virgo Online Processing}

Once data (under frame format) have been collected, they must also be processed online. First step of this processing is the calibration of the data (reconstruction of equivalent gravitational wave strain $\mathrm{h}$ ) and the check of their quality (essentially by using environment monitoring data). Last step is the reduction of the amount of data before any offline data analysis. This is the purpose of the Online Preselection.

A flux of $4 \mathrm{MB} / \mathrm{s}$ means about $345 \mathrm{~GB}$ per day and $126 \mathrm{~TB}$ per year. Using the Online Preselection, we aim at reducing this amount to a maximum of 5 TB per year, with the hope to go below 1 TB per year. The current general architecture of the Virgo Online Preselection is based on a master/slaves approach, where a central machine and software (Trigger Manager) is in charge of receiving frames, sending specific data ( $h$ values) to each node of a cluster of machines, receiving algorithms results and selecting the frames. The whole system is based on a 100 Mbps Ethernet network and TCP/IP communication protocol.

\section{Conclusion}

The Virgo Data Acquisition is on the way to be complete. Hardware is installed and software is currently under optimization and long term tests. It is based on Ethernet $100 \mathrm{Mbps}$ and $1 \mathrm{Gbps}$ networks, the use of frame format and Frame Builders. Shared memory and dynamical connection philosophy allows any user to monitor data easily without disturbing the data acquisition main stream.

The Virgo Online Processing workstations are already installed on Virgo site. Softwares for h Reconstruction, Data Quality check and Online Preselection are under development.

\section{References}

1. B. Mours, "Specification of a Common Data Frame Format for Interferometric Gravitational Wave Detectors", Virgo Note VIR-SPE-LAP-5400-102 and Ligo Note LIGO-T970130-B.

"Frame's Library User's Manual", Virgo Note VIR-MAN-LAP-5400-103 (v4r11).

See also http://wwwlapp.in2p3.fr/virgo/FrameL

2. D. Verkindt et al. "Data Acquisition schemes", Virgo Note April 2000, VIRMAN-LAPP-5400-110. 